\title{
História em quadrinhos no Ensino de Ciências por investigação, uma experiência do programa residência pedagógica, BIO-FACEDI
}

\section{History in comics in the teaching of sciences by research, an experience of the pedagogical residence program, BIO-FACEDI}

\author{
Maria Milena Pires Lima ${ }^{1}$ \\ Nirla do Nascimento Barbosa ${ }^{2}$ \\ Isabel Cristina Higino Santana ${ }^{3}$
}

Resumo: Vivenciar a prática da sala de aula é um dos objetivos do Programa Residência Pedagógica. Diante disso, o presente artigo, que tem como objetivo narrar uma vivência realizada durante o segundo módulo do subprojeto residência pedagógica do curso de Ciência Biológica da Faculdade de Educação de Itapipoca. A regência ocorreu no ensino remoto emergencial - ERE, devido o momento atual atípico. A experiência ocorreu na escola Francisca de Morais Pontes, parceira no subprojeto, para uma turma de $7^{\circ}$ ano, e envolveu como tema, as doenças transmissíveis com destaque para o ensino de vírus, atraves da abordagem do ensino de ciência por investigação usando como ferramenta de ensino as Histórias em Quadrinhos (HQ). Essa experiência destaca êxito através da abordagem do ensino de Ciência por investigação a partir de HQ.

Palavras-chave: Atividade Investigativa. Recurso Didático. Ensino de Ciência.

Abstract: Experiencing the practice of the classroom is one of the objectives of the Pedagogical Residency Program. Therefore, this article, which aims to narrate an experience held during the second module of the pedagogical residency subproject of the Biological Science course at the Itapipoca School of Education. The regency takes place in emergency remote education - ERE, due to the atypical current moment. An experience that took place at the Francisca de Morais Pontes school, a partner in the subproject, for a 7th grade class, and involved as a theme, communicable diseases, with emphasis on the teaching of viruses,

\footnotetext{
${ }^{1}$ Bolsista residente e graduanda do curso de Ciências biológica da Faculdade de Educação de Itapipoca. Av. Da Universidade S/N - madalenas. Itapipoca-Ceará. E-mail: maria.pires@aluno.uece.br

${ }^{2}$ Professora da Rede Municipal de Ensino de Itapipoca-Ceará - Rua Inocêncio Braga S/N. Itapipoca- Ceará. Email: nirlabarbosa@yahoo.com.br

${ }^{3}$ Professora Curso de Ciências Biológicas da Universidade Estadual do Ceará /Faculdade de Educação de Itapipoca-FACEDI/UECE. Av. Da Universidade - S/N. Itapipoca -Ceará. E-mail: isabel.higino@uece.br
}

Recebido em 23/01/2022

Aprovado em 10/02/2022

Sistema de Avaliação: Double Blind Review

OPEN ACCESS 
through the approach of teaching science through investigation using as a tool for I teach as Comics (HQ). This experience stands out through the approach of science teaching by investigation from HQ.

Keywords: Investigative Activity. Didactic Resource. Science Teaching.

\section{Introdução}

O Programa Residência Pedagógica (RP) tem como um de seus objetivos, proporcionar aos estudantes de cursos de licenciatura, a oportunidade de vivenciar a prática da docência a partir da segunda metade do curso (CAPES, 2018). E o subprojeto Residência Pedagógica do curso de Ciências Biológicas da Facedi (RPBioFACEDI), tem como objetivos além da formação de professores, divulgar e estimular o ensino de Ciências por meio da abordagem do Ensino por Investigação.

O Ensino por investigação (EI) também conhecido pelo termo, atividade investigativa, propõe que o aluno possa ser protagonista da sua aprendizagem e no RPBioFACEDI utilizou-se dessa abordagem aliada ao uso de sequências didáticas. "A sequência de Ensino por Investigação é uma metodologia de ensino que envolve determinados procedimentos conexos, que permitem aos sujeitos envolvidos a atuação ativa nas atividades propostas para a aprendizagem" (SOUZA, 2017, p. 06). Nessa perspectiva, as sequências de ensino investigativas ( SEI) promovem a autonomia do aluno em busca do seu aprendizado.

Segundo Sasseron (2015) o Ensino de Ciência Por Investigação (ENCI) pode ser considerado como uma abordagem didática, podendo ser utilizado em diversos contextos: “ $\mathrm{O}$ ensino por investigação extravasa o âmbito de uma metodologia de ensino apropriada apenas a certos conteúdos e temas, podendo ser colocada em prática nas mais distintas aulas, sob as mais diversas formas e para os diferentes conteúdos" (SARRESON, 2015, p. 58).

Assim, entre as diversas formas citadas, podemos destacar o uso das histórias em quadrinhos(HQ'S) e que seu uso pode proporcionar uma melhor compreensão dos conteúdos de ciências, pois são consideradas obras ricas em simbologias e podem ser vistas como objeto de lazer, estudo e investigação.

Mediante sua linguagem própria, as histórias contadas por meio de sequências de imagens se tornaram uma das formas mais simples e diretas para a transmissão de ideias, oferecendo inúmeras possibilidades para o exercício da leitura. Além disso, contribuem para o desenvolvimento da competência de interação entre leitor e texto por meio de um processo de 
descoberta, tornando a leitura uma tarefa desafiadora e, até mesmo, lúdica (VERGUEIRO, 2004).

Dessa forma, o objetivo principal deste trabalho é relatar uma experiência vivida durante o segundo módulo do subprojeto em que foram utilizadas as HQ's e a sequência didatica através da abordagem de ensino por investigação, considerando o momento atípico e a utilização de tecnologias digitais para execução das regências através do Ensino Remoto Emergencial-ERE.

\section{Histórias em quadrinhos como ferramenta de ensino}

As Histórias em Quadrinhos (HQ's) vêm ao longo do tempo se configurando como um material didático bastante eficaz no processo de ensino e aprendizagem. Assim, com base em (KRAKHECKE, 2009 APUD DELFINO, 2015), as histórias em quadrinhos (HQ) vêm a ser constituídas de um conjunto de tiras no qual apresentam imagens com textos formando uma história, que pode vir a ser curtas ou longas e assim formando uma sequência.

O professor está sempre em busca de ferramentas, estratégias e metodologias de ensino que dinamizem suas aulas e contribuam significativamente para o processo de ensino e aprendizagem, possibilitando autonomia e criticidade ao estudante. Seja ela para favorecer na compreensão dos assuntos (temas vistos como de dificil entendimento) ou mesmo para colabora na precepção de conteúdos algumas vezes considerados "chatos".

Dessa forma, as Histórias em Quadrinhos podem ser consideradas como uma dessas ferramentas de ensino que ajudam na compreensão de diversos temas trabalhados em sala de aula pelos professores e que buscam tornar a aula mais dinâmica e divertida, para os alunos, uma vez que as HQ'S já fazem parte do cotidiano dos alunos.

Nessa perspectiva, como afirma Carvalho (2010), o HQ já faz parte do cotidiano das crianças e cabe a escola a valorização esse material em atividade didática. Pela grande popularidade das HQ'S, os professores vêm utilizando-as cada vez mais, uma vez que seu reconhecimento como instrumento didático está em documentos oficiais como, Lei de Diretrizes e Bases - LDB (1996) e pelos Parametros Curriculares Nacionais - PCNs (2002). Além disso, as imagens e simbologias apresentadas nas HQ's tornam essa ferramenta de ensino multidisciplinar. 


\section{Sequência de ensino investigativo (SEI)}

A sequência didática (SD) é uma excelente forma que o professor tem de organizar as suas aulas, e é definida por Zabala (1998, p.53) como "uma série ordenada e articulada de atividades que compõem cada unidade temática". Ou seja, a mesma se preocupa na organização dos assuntos a serem trabalhados pelo professor de maneira contínua que vai para além do trabalho elaborado em um plano de aula. $\mathrm{Na} S \mathrm{D}$, o professor tem o tema geral a ser trabalhado, assim como a lista de conteúdos sendo eles: conceituais procedimentais e atitudinais, assim tambem como o tempo estimado, as habilidades da BNCC e a organização da turma.

Por outro lado, o Ensino de Ciências Por investigação (ENCI), segundo Spencer e Walker (2011) tem sua origem relacionada às ideias de John Dewey, que são a valorização da importância de possibilitar ao aluno que este utilize habilidades de pensamento crítico e reflexivo. Neste sentido, o professor de Ciências deve criar possibilidades para que o aluno seja capaz de buscar a autonomia para a sua aprendizagem, que o aluno saia da visão de uma aula tradicional onde ha o professor, quadro-giz e alunos silenciosos para uma aula que os estudantes sejam protagonistas do seu processo de ensino e aprendizagem, sejam alunos de mentes pensantes, críticos, reflexivos e capazes de opinar sempre que o ambiente da sala de aula for favorável.

Assim, a utilização de uma sequência de ensino investigativo nas aulas de Ciências faz valer o que está presente no objetivo dos Parâmetros Nacionais Curriculares PCN's (1998, p.08) que diz: "Questionar a realidade formulando-se problemas e tratando de resolvê-los, utilizando para isso o pensamento lógico, a criatividade, a intuição, a capacidade de análise crítica, selecionando procedimentos e verificando sua adequação".

Desse modo, o uso de atividades investigativas, fortalece a formação de cidadãos pensantes, criticos e reflexivos para a sociedade. Além disso, possibilita ao educando o protagonismo no seu processo de aprendizagem.

\section{Metodologia}

Este trabalho trata-se de um relato de experiência, pois, visa descrever uma experiência vivida dentro do subprojeto RPBioFACEDI, que aconteceu durante as regências, 
momento em que o residente exercita a prática pedagógica da sala de aula.

A referida experiência ocorreu na primeira etapa da sequência de ensino investigativo (SEI), o que culminou na primeira regência do segundo módulo do subprojeto. A atividade foi realizada de forma remota, devido ao atual momento vivenciado pela pandemia do SARSCoV-2 (COVID-19). Nesse contexto, a proposta da SEI deu-se de forma síncrona pelo aplicativo do Google Meet e assíncrona através de vídeo-aula disponibilizada na plataforma Youtube e posteriormente, disponibilizada no grupo de Whatsapp.

O subprojeto foi desenvolvido na escola de Educação básica Francisca de Morais Pontes, localizada na sede urbana do município de Itapipoca no interior do estado do Ceará, para uma turma do $7^{\circ}$ ano do ensino fundamental II que tem como público-alvo, adolescentes na faixa étaria entre 11 e 12 anos.

A SEI foi elaborada para ser desenvolvida em 4 aulas assíncronas e síncronas, com duração média de 40 minutos para cada uma delas, abordando a temática, Doenças Transmissiveis, conteúdo presente no currículo escolar, que está em consonância com a Base Nacional Comum Curricular (BNCC) e com as Orientações Curriculares Prioritárias do Ceará (OCPC).

Na primeira aula foi trabalhado o tema Nossas Defesas, assim como vacinas e outros medicamentos. Na segunda aula foi abordado doenças causadas por vírus, destacando-se: gripe, resfriado, poliomielite, sarampo, rubéola, catapora, caxumba e raiva. A terceira aula foi a continuidade ao estudo das doenças causas por vírus desta vez tratando sobre: dengue, febre amarela, chikungunya e zika. E para encerrar a sequência investigativa a quarta aula foi uma socialização prevista na terceira aula, momento em que todos compartilham o conhecimento adquirido ao longo das aulas.

Para a coleta e análise dos dados utilizou-se a abordagem descritiva argumentativa, buscando amparo na literatura específica.

\section{Resultados e discussão}

A atividade investigativa realizada na primeira etapa da SEI, iniciou-se mediante a apresentação do conteúdo de maneira assíncrona e síncrona, utilizando Plataformas digitais como descrito anteriormente.

Em seguida, aconteceu o diálogo com a turma sobre o conteúdo a ser abordado e 
sobre a utilização da HQ. Nesse momento, perguntou-se aos mesmos sobre o que conheciam a respeito de HQ's e se gostavam de ler esse tipo de gênero textual. Em seguida, foi apresentada uma HQ, que abordava o conteúdo trabalhado na aula. E no final havia um problema para ser resolvido. Nesse momento da aula, os alunos foram estimulados a pensar soluções para o problema apresentado na história (Figura 1). No entanto, essa resposta para a problemática da HQ deveria ser apresentada através de HQ's, com a socialização por meio do Google Meet (Figura 2). Nesta etapa da sequência, a ideia foi de valorizar a abordagem do ensino por investigação.

Figura 1: Proposta Investigativa

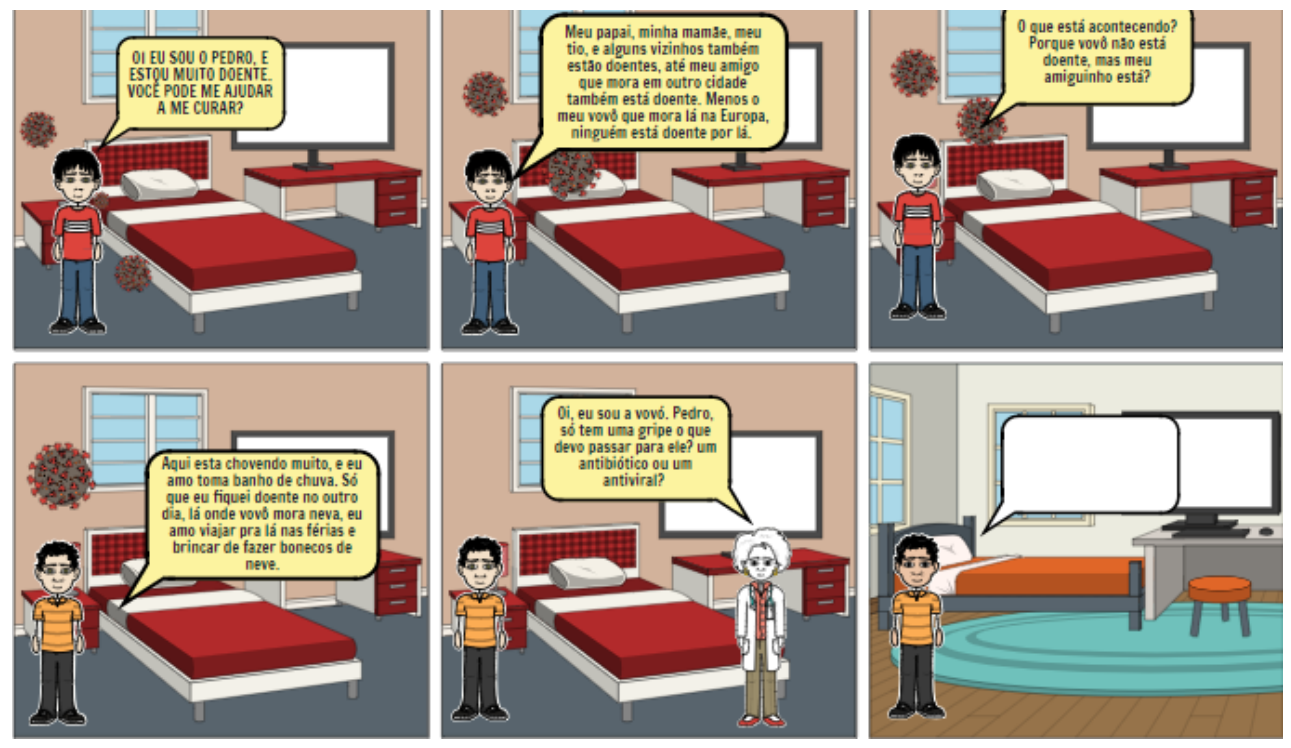

Fonte: Arquivo pessoal das autoras.

Assim, os alunos o fizeram. Criaram um final para a HQ, que se tratava da solução para o problema proposto. $\mathrm{Na}$ aula seguinte, foi o momento da socialização da atividade prosposta. Foram apresentadas várias soluções para a problemática, assim como, muitos símbolos e desenhos representando o final da HQ. O que nos fez perceber a identificação da turma com a atividade proposta.

Partindo dessa premissa, após a socialização, ficou evidente a compreensão dos alunos pelo tema trabalhado na proposta investigativa, onde a mesma tinha como objetivo encontrar uma solução para o problema proposto na HQ, assim como a habilidade dos mesmos em criar simbolos e desenhos representativos do texto. Tal evidencia, corrobora com as ideias de Caruso e Silveira (2009), onde os mesmos afirmam que é prioridade na utilização das HQ'S como ferramenta didática que o aluno só deve criar suas tirinhas depois de aprender e refletir sobre um determinado conceito, simbologia e imagens. "Ele não pode 


\section{REVISTA MULTIDISCIPLINAR}

\section{HUMANIDADES E TECNOLOGIAS (FINOM)}

ser visto apenas como o desenhista que, mecanicamente, dará vida a uma ideia do professor. Sua criação deve ser fruto de um processo interativo, reflexivo e questionador ( CARUSO e SILVEIRA 2009, p. 221).

Assim, foi possivel perceber após análise das atividades socializadas, que os alunos entenderam a atividade, articulando a mesma com aspecto do ensino por investigação, na realização de pesquisa, leitura, compreensão, argumentação e socialização atraves do HQ (Figura 2).

\section{Figura 2: Socialização da proposta investigativa}

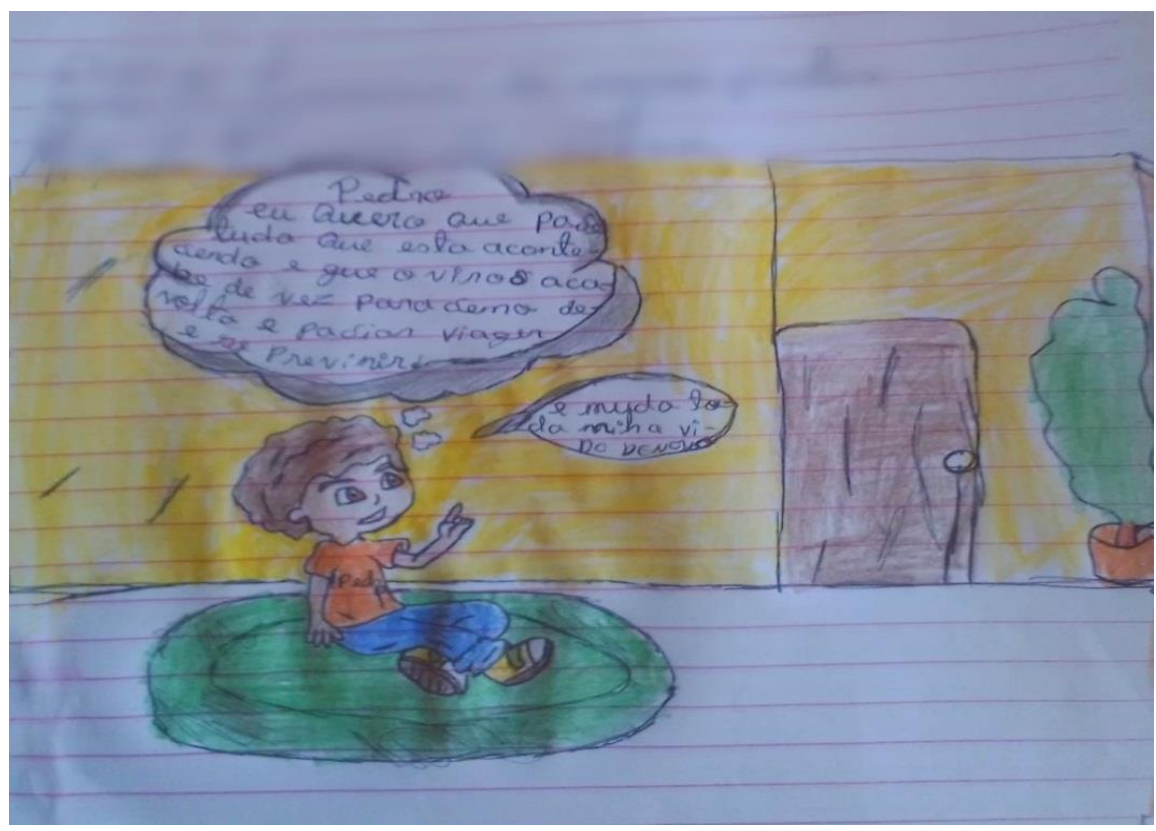

Fonte: Arquivo pessoal das autoras

Desse modo, ao analisar a atividade realizada pela turma de forma individual, viu-se que os alunos têm habilidade do desenho e a capacidade de associar tais desenhos com o texto escrito, o que nos faz perceber que esse gênero textual poderia ser explorado mais vezes dentro da sala de aula. Por outro lado, percebeu-se também que alguns alunos apresentam muita dificuldade em realizar desenhos associativos com texto escrito. Diante disso, viu-se que esse gênero textual poderia ser trabalhado de diversas maneiras dentro da sala de aula, até mesmo como oficina para possibilitar ao aluno que não tem habilidade na produção de $\mathrm{HQ}$, a oportunidade de desenvolver tais habilidades.

A etapa da socialização foi um momento rico para as trocas de conhecimentos e aprendizagens dos alunos, nesse processo de produção do HQ, pois, ficou claro que muitos já têm essa prática de produzir tirinhas, retratando muitas vezes em suas produções, situações do dia a dia, sentimentos, emoções, etc. No entanto, nem sempre esse material produzido fica 
disponivel, sendo esquecido. É importante que esses momentos possam ser compartilhados e divulgados ( na escola mesmo), pois, favorece nao apenas na produção do conhecimento, mais na valoriação do aluno e de sua auto-estima. Silva (2010) argumenta que a produção de quadrinhos induz a criatividade da criança, "motivam a discussão e a reflexão e, principalmente, estimulam uma leitura mais apurada da realidade vivida e a desmistificação do discurso ideológico que perneia as relações sociais e políticas do mundo" (SILVA, 2010, p. 14).

Além disso, a linguagem simples e clara dessa ferramenta multidisciplinar é capaz de estimular o lado investigativo e a aprendizagem de crianças e jovens, pois significa o conteúdo aprendido, ao tornar a aula mais agradável, interativa, dinâmica e dialógica, permitindo assim a exposição de ideias, ponto de vista e o pensamento crítico.

Desse modo, viu- se o quanto as HQ'S são viáveis como ferramentas didáticas no processo de ensino e aprendizagem, uma vez que promovem maior interação entre professor aluno- conteúdo, possibilitando assim, a interação, o contra de vivências e experiencias e a contrução de saberem diversos.

\section{Considerações finais}

Ao longo desse trabalho ficou claro que a utilização de uma ferramenta didática como o HQ, contribui significamente para a aprendizagem dos estudantes, uma vez que se utilizando de uma linguagem simples, clara e mais próxima da realidade dos alunos pode favorecer a aprendizagem.

Ao considerarmos o HQ como uma ferramenta multidisciplinar, percebemos que sua utilização no ambiente da sala de aula é um aspceto positivo e que se adequa em todas as áreas, uma vez que favorece não somente a aprendizagem dos assuntos de Ciências, mas, saberes diversos.

Ressaltamos ainda, que uma ferramenta didática acessível e mais próxima da línguagem dos alunos favorece a aprendizagem dos estudantes, pois, possibilita que o aluno seja o autor do seu processo de aprendizagem, onde o mesmo será estimulado a colocar em prática seu lado criativo, reflexivo e cientifico.

É notório, que a abordagem do HQ no Ensino de Ciências por Investigação, a partir de sequências investigativas, favorece a curiosidade, a busca por respostas, soluções e que estimula na criança e jovem o lado crítico e protagonista, tão necessário de estudo das 
ciências e da formação de um indivíduo consciente da importância da Ciência e do conhecimento cientifico.

Diante do exposto, reafirmamos a importância do uso do HQ como ferramenta didática nas aulas de Ciências.

\section{Referências}

BRASIL. Ministério da Educação. PCN+Orientações Educacionais Complementares aos Parâmetros curriculares Nacionais - Ciências da Natureza, Matemática e suas Tecnologias. 2002.

Brasil. Secretaria de Educação Fundamental. Parâmetros curriculares nacionais Ciências Naturais /Secretaria de Educação Fundamental. . Brasília : MEC /SEF, 1998.

CAPES. Coordenação de Aperfeiçoamento de Pessoal de Nível Superior. Edital 6: Chamada Pública para apresentação de proposta no âmbito do Programa de Residência Pedagógica. Brasília: Ministério da Educação, 2018.

CARUSO, F.; SILVEIRA, C. Quadrinhos para a cidadania. História, Ciências, SaúdeManguinhos, Rio de Janeiro, v. 16, n. 1, p. 217-236, jan.-mar. 2009.

CARVALHO, L. DOS S., \& MARTINS, A. F. P. (2009). Os quadrinhos nas aulas de Ciências Naturais: uma história que não está no gibi. Revista Educação Em Questão, 35(21). Recuperado de https://periodicos.ufrn.br/educacaoemquestao/article/view/3959 Acessado em: 17 Dez. 2021.

DELFINO, Vinícius Siqueira; ALMEIDA, A. S.; DIAS, A. M. L. O uso de HQ no ensino da geografia: diferentes linguagens em sala de aula. In: In: II Congresso Nacional de Educação, Campina Grande. Anais... Campina Grande. 2015.

HILÁRIO, T.W., e SOUZA,R.R. Sequência de ensino por investigação: uma proposta para o processo de alfabetização: produto educacional vinculado à dissertação... [ manuscrito] Câmpus Jataí. 2018.

SASSERON, L.H. Alfabetização científica, ensino por Investigação e Argumentação: relações entre Ciências da Natureza e Escola. Revista Ensaio, Belo Horizonte, v.17 n.especial, p. 49-67, novembro, 2015.

SILVA, E. I. A linguagem dos quadrinhos na mediação do ensino de Geografia: Charges e quadrinhos no usa da cidade. Universidade Federal de Goiás. Goiânia, 2010.

SPENCER, T. S., e WALKER, T. M. Creating a Love for Science for Elementary

Students through Inquiry-based Learning. Journal of Virginia Science Education, 4(2), 1825. 2011. 


\section{REVISTA MULTIDISCIPLINAR}

ISSN 1809-1628

VERGUEIRO, W. Como usar histórias em quadrinhos na sala de aula. São Paulo: Contexto, 2004.

ZABALA, Antoni. A prática educativa - como ensinar. Porto Alegre: Artmed, 1998. 